\title{
Life Time Cycle in Power Electronics for Fuzzy Logic Speed Controller in Brushless Motors
}

\author{
Manuel García-López ${ }^{1}$, José A. Rosales-Martinez ${ }^{2}$, Pedro Ponce-Cruz ${ }^{2}$, \\ Arturo Molina-Gutiérrez ${ }^{2}$, José J. Rodríguez Rivas ${ }^{1}$ \\ ${ }^{1}$ Instituto Politécnico Nacional, \\ Mexico \\ ${ }^{2}$ Tecnológico de Monterrey, Ciudad de México, \\ Mexico \\ \{magarcial, jjrodriguezr\}@ipn.mx, \\ \{antonio.rosales, pedro.ponce, armolina\}@itesm.mx
}

\begin{abstract}
Power electronic modules are subject to a variety of temperature profiles caused by cyclic thermo-mechanical stress on joints causing device failure. This paper shows how the life time cycle of the power electronic converter is affected in a fuzzy speed controller for a brushless DC motor drives (BLDC). Although there are several papers that show the performance of fuzzy logic speed controllers, there are not enough papers that show how the life time in power electronics is affected according to the power electronic stage losses. Thus, the losses in the power electronic stage are not included into the design of the controller. As a result, the industrial process in which brushless motor drives are installed, decrement their life time. This paper estimates the lifetime cycle in the power electronics stage when a fuzzy logic speed controller is implemented in BLDC. The analysis is based on co-simulation between LabVIEW and Multisim to calculate the response, stablished by the fuzzy logic controller, of temperature because to power losses conduction/switching of the semiconductor (IGBTs), on power electronic stage and the speed control. A comparison between a conventional linear controller and a fuzzy logic controller also is conducted and the results show a superior response in the speed response. In addition, the losses in the power electronic stage are reduced when the fuzzy logic speed controller is implemented. Hence, the fuzzy logic design is evaluated according to the speed response and lifetime in the power electronic stage.
\end{abstract}

Keywords: power electronic, fuzzy logic controller, life time cycle, brushless DC motor.

\section{Introduction}

Brushless DC motors (BLDCM), are widely used in the industry since they provide advantageous properties as large lifetime, noise robustness, good enough torque- 
velocity ratio, smaller size and higher efficiency than inductions motors, and rotor losses in BLDCM are minor compared with those in induction machines [1, 2]. Position and speed regulation and/or tracking are commonly the control objectives for a BLDCM i.e. position control is employed in space crafts and servomechanism while speed control is important in robotics, [3, 4]. However, the power electronics (power converter), essential to drive the BLDCM and accomplish the control objectives, is not studied or analyzed deeply even this is neglected in most of the cases.

Commutation frequency of power electronics, supply voltage, and tracking commands, are vital conditions for power electronics in BLDCM control applications [5]. These conditions generate a variety of operation modes producing temperature profiles causing cyclic thermo-mechanical stress on power electronic devices $[6,8]$. The lifetime expectations of power electronic devices, is defined in terms of the frequency and magnitude of the thermo-stress cycles [6,8]. The consideration of these operation modes in terms of thermal stress on the design of control strategies, can extend hugely the lifetime of the power electronic devices having direct effects in economic savings $[5,6,7]$.

Discrete power semiconductors are applied on different areas depending of power requirements and operation frequency. For example, SCRs and GTOs are employed on high-power applications while IGBTs and MOSFET are used on high-frequency applications. Then, considering the are application and control requirements, a variety of power semiconductors are available to be utilized, see [12].

Linear and nonlinear controllers have been designed to ensure the control goals despite disturbances and uncertainties demanding a high performance to power electronics guarantying accuracy, precision, and robustness, in return for a shorter lifetime of power electronics [7]. In this paper, a Fuzzy logic control to regulate the speed on a BLDCM, considering thermo-stress to estimate lifespan of power electronics (h-bridge), is presented. Main advantages of Fuzzy control are: facility to control nonlinear systems without mathematical model; work as adaptive control, commonly Fuzzy techniques are combined with classical PID and nonlinear controller techniques to adapt controller's gains; potential to work as multi-input controllers; and the most important is the capability to encapsulate information from operators adding human knowledge and experience in the performance of the controller [9].

In this research work, the analysis and estimation of lifetime in power electronics for BLDCM speed control is validated via co-simulation LabView ${ }^{\mathrm{TM}}-\mathrm{Multisim}^{\mathrm{TM}}$. Cosimulation is understood as the integration of two simulation platforms to form an integrated system where a constant exchange of data between both simulations platforms is maintained. For emulation of BLDCM speed control, co-simulation LabView $^{\mathrm{TM}}$-Multisim ${ }^{\mathrm{TM}}$ is a valuable option since Multisim ${ }^{\mathrm{TM}}$ contain accurate models of DC drives and power electronics (including thermal analysis), while LabView ${ }^{\mathrm{TM}}$ is an useful software for control systems simulation [10]. The contribution of this paper is the design of a fuzzy control to regulate the speed of a BLDCM, dealing with temperature profiles caused by desired tracking commands, lifetime of power electronics is estimated using the temperature profiles produced by the control specifications, the temperature profiles are obtained from the co-simulation LabView $^{\mathrm{TM}}$-Multisim ${ }^{\mathrm{TM}}$. 
It is highly recommended that a fuzzy logic controller is designed the speed response has to be achieved but also the thermal response of the power electronics stage has to be analyzed during the design stage. Moreover, it is required that a co-simulation validates the thermal losses in the power electronics stage. If thermal losses are not studied, the lifetime of the electric drive is reduced.

\section{Brushless Motor and Converter}

The dynamics of BLDCM are described by equation (1):

$$
\dot{x}=\left[\begin{array}{ccccc}
-\frac{R_{s}}{L_{1}} & 0 & 0 & -\frac{\lambda_{p}}{J} f_{a s\left(\theta_{r}\right)} & 0 \\
0 & -\frac{R_{s}}{L_{1}} & 0 & -\frac{\lambda_{p}}{J} f_{b s\left(\theta_{r}\right)} & 0 \\
0 & 0 & -\frac{R_{s}}{L_{1}} & -\frac{\lambda_{p}}{J} f_{c s\left(\theta_{r}\right)} & 0 \\
\frac{\lambda_{p}}{J} f_{a s\left(\theta_{r}\right)} & \frac{\lambda_{p}}{J} f_{b s\left(\theta_{r}\right)} & \frac{\lambda_{p}}{J} f_{c s\left(\theta_{r}\right)} & -\frac{B}{J} & 0 \\
0 & 0 & 0 & \frac{P}{2} & 0
\end{array}\right]\left[\begin{array}{c}
i_{a s} \\
i_{b s} \\
i_{c s} \\
\omega_{m} \\
\theta_{r}
\end{array}\right]+\left[\begin{array}{cccc}
\frac{1}{L_{1}} & 0 & 0 & 0 \\
0 & \frac{1}{L_{1}} & 0 & 0 \\
0 & 0 & \frac{1}{L_{1}} & 0 \\
0 & 0 & 0 & \frac{1}{J} \\
0 & 0 & 0 & 0
\end{array}\right] u,
$$

where $u=\left[\begin{array}{llll}v_{a s} & v_{b s} & c_{c s} & T_{l}\end{array}\right]^{T}$.

The movement of BLDCM is driven by the current applied on the stator coils that generates a magnetic field orthogonal in the direction of the magnetic field produced by the permanent magnets. Once the movement begins, the rotor position changes constantly, and the position of the rotor must be measured to excite the corresponding coil to the permanent magnet $[10,11]$. A common circuit to drive BLDCM's (composed by voltage source, 3-phase inverter, and three Hall Effect sensors) is the presented in Fig. 1.

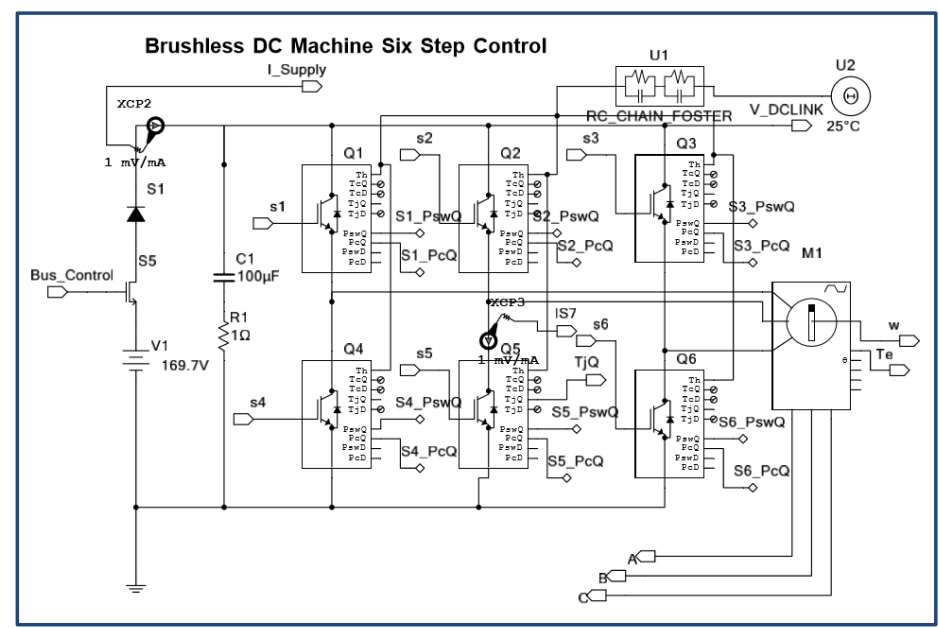

Fig. 1. BLDCM drive co-simulation in Multisim ${ }^{\mathrm{TM}}$. 


\subsection{Semiconductor Losses and Lifetime}

Power losses in IGBT module consists of the sum of power losses of IGBT chips and FWD chips. Power losses can be classified as either on-state losses or switching losses. The on-state power losses of the IGBT are calculated by $P_{C T}=u_{C E O} * I_{C a v}+r_{c} I_{C r m s}^{2}$ and can be estimated using the output characteristic shown in Fig. 2(a). The diode on-state power losses are calculated by $P_{C D}=u_{D O} * I_{D a v}+r_{D} I_{D r m s}^{2}$ and can be estimate using the output characteristic shown in Fig. 2(b). The turn-on energy losses in IGBT are calculated by $E_{\text {onT }}=\int_{\text {ton }}\left(u_{C E O} * i_{C}(t)\right) d t$, the turn-off energy losses by $E_{\text {offT }}=$ $\int_{\text {toff }}\left(u_{C E O} * i_{C}(t)\right) d t$ and the turn-on energy in the diode mostly of the reverse-recovery energy is calculate by $E_{\text {onD }}=\int_{\text {ton }}\left(u_{D}(t) * i_{F}(t)\right) d t$.

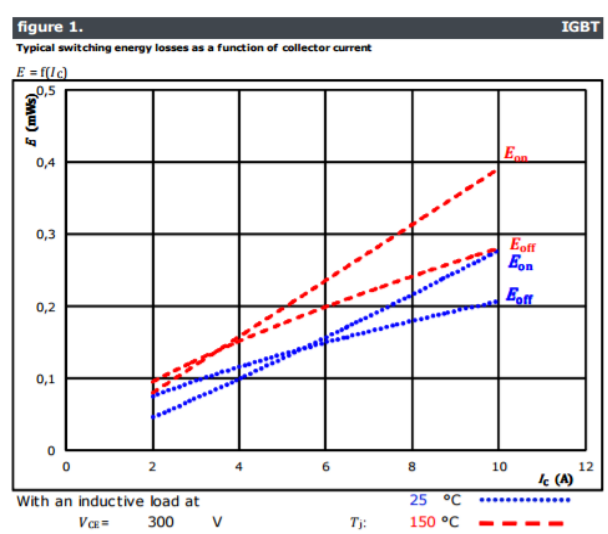

Fig. 3. Typical switching energy losses as a function of collector current.

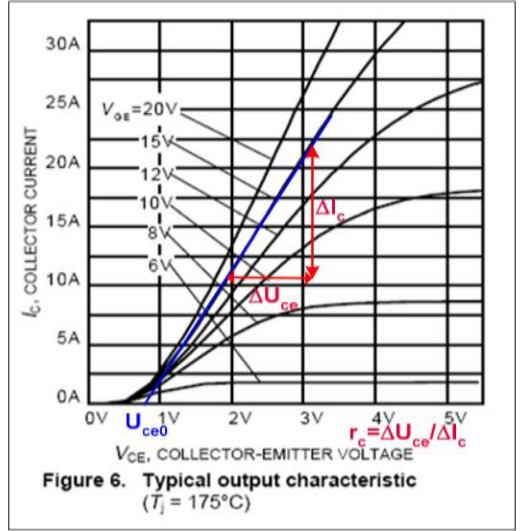

a)

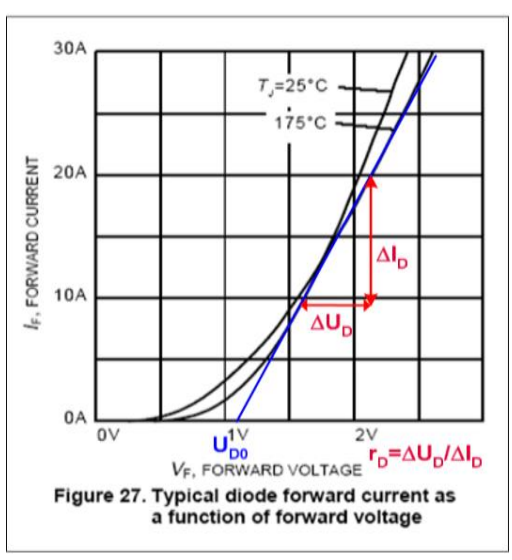

b)

Fig. 2. (a) Reading the $u_{C E O}$ and $r_{c}\left(r_{c}=\Delta U_{c e} / \Delta I_{c}\right)$ from the data-sheet diagram, (b) Reading the $u_{D O}$ and $r_{D}\left(r_{d}=\Delta U_{c e} / \Delta I_{c}\right)$ from the data-sheet diagram: 
The switch-off losses in the diode are normally neglected $E_{\text {off } D} \approx 0$. The switching losses in the IGBT are calculated by $P_{S w T}=\left(E_{\text {onT }}+E_{\text {off } T}\right) * F_{S w}$ and in the diode are the product of switching energies and the switching frequency $\left(F_{S W}\right)$ and are calculated by $P_{s w D}=\left(E_{\text {onD }}+E_{\text {offD }}\right) *\left(F_{S w}\right) \approx E_{\text {onD }} *\left(F_{s w}\right)$. The losses total are calculated by equation (2):

$$
W=P_{C T}+P_{S w T}+P_{C D}+P_{S w D}
$$

The switching losses in the IGBT can be calculated from switching vs. collector current characteristics as it is shown the Fig. 3. The diode switching losses can be calculated in analogous manner [15].

The heat conduction of a semiconductor can be simulated in an electric circuit with one IGBT module mounted on a heat sink this circuit is shown in Fig. 4(a). Using the equivalent circuit of Fig. 4(a), where $W$ is module power loss, $T_{j}$ is junction temperature IGBT chip, $T_{f}$ is temperature of heat sink, $T_{c}$ is module case temperature, $T_{a}$ is ambient temperature, $R_{t h(j-c)}$ is thermal resistance between case and heat sink, $R_{t h(c-f)}$ is contact thermal resistance between case and heat sink, and $R_{t h(f-a)}$ is thermal resistance between heat sink and ambient air.

The junction temperature $T_{j}$ can be calculated using the thermal equation (3) [15]:

$$
T_{j}=W *(R \operatorname{th}(j-c)+R \operatorname{th}(c-f)+R \operatorname{th}(f-a))+T a .
$$

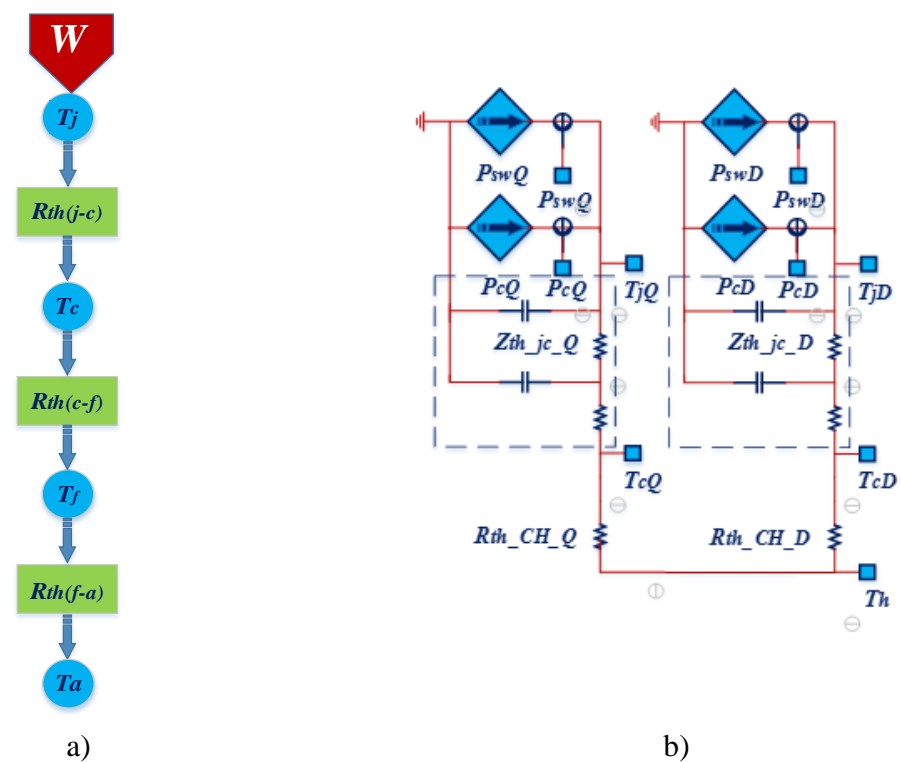

Fig. 4. (a) Thermal resistance equivalent circuit, (b) Electro-Thermal model. 


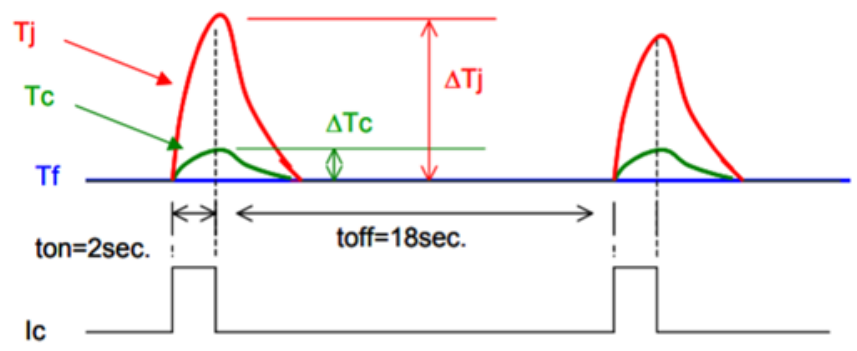

Fig. 5. Pattern diagram of current flow of $\Delta \mathrm{T}_{-} \mathrm{j}$ power cycle and temperature change.

Modeling of commutation and conduction losses as well as the temperature profiles on IGBT junction is done by electro-thermic networks considering averages on a modulation period [14], see Fig. 4(b).

The power cycle life can be calculated from the power cycle capability curve that shows the relation between the temperature change $\Delta T_{j}$ and the number cycles. The power cycle capability curve is the life curve made when the junction temperature rapid rises and falls.

In these curves, failure caused by deterioration at the interface between the aluminum bonding wire and chip surface interconnection is observed. Fig. 5. shows the patterns of current flow in the $\Delta T_{j}$ power cycle test. During the $\Delta T_{j}$ power cycle test the junction temperature goes up and down in a short time cycle; therefore, outstanding temperature difference between silicon and bonding wire results in thermal stress. The $\Delta T_{j}$ power cycle lifetime is mainly limited by the aluminum bonding wire joints. Fig. 13(a) shows the power cycle capability curve of the IGBT module to $\Delta T_{j \min }=25^{\circ} \mathrm{C}$ and to $\Delta T_{\text {jmax }}=150^{\circ} \mathrm{C}[15]$.

The power cycles capability can be calculated by equation (4):

$$
C F=541162959016419 * \Delta T^{-5.12121},
$$

where $\Delta T=P_{t} Z_{t h}, P_{t}=I_{r m s}^{2} R_{o n}$, and $Z_{t h}=2.3354 F_{r}^{-0.165}$. The Time Before Failure (TBF) can be calculate by equation (5):

$$
T B F=\frac{C F}{F r} * 60 * 24 * 265 \text { years. }
$$

where $F_{r}$ is the frequency of the thermal oscillations.

\section{$3 \quad$ Fuzzy Logic Speed Control Design}

Fuzzy control is a qualitative control strategy emulating expert knowledge. In order to satisfy the control objective, the control law in equation (6) is applied: 


$$
\begin{gathered}
u=\sum_{i=1}^{4} \sum_{j=1}^{4} \sum_{k=1}^{4} v_{i} w_{j} q_{k}\left(a_{0 i j k}+a_{2 i j k} e_{I}+a_{3 i j k} e_{D}+a_{4 i j k} e_{P} e_{I}+\right. \\
\left.a_{1 i j k} e_{P}+a_{5 i j k} e_{P} e_{D}+a_{6 i j k} e_{I} e_{D}+a_{7 i j k} e_{P} e_{I} e_{D}\right),
\end{gathered}
$$

where the logic variables are $v_{i}, \omega_{j}, q_{k}$ contain the information of the input membership functions with, $\quad v_{1}=\left\{\begin{array}{ll}1 \text { for } e_{P} \leq e_{P 1} \\ 0 & \text { otherwise }\end{array} v_{2}=\left\{\begin{array}{cc}1 \text { for } e_{P I}<e_{P} \leq e_{P 2} \\ 0 & \text { otherwise }\end{array} ; v_{3}=\left\{\begin{array}{cc}1 \text { for } e_{P 2}<e_{P} \leq e_{P 3} \\ 0 & \text { otherwise }\end{array} ; v_{4}=\right.\right.\right.$ $\left\{\begin{array}{ll}1 \text { for } e_{P 3} \leq e_{P} & \\ 0 & \text { otherwise }\end{array}\right.$ other variables can be computed similarly as $w_{j}, q_{k}$.

A useful methodology to design fuzzy logic controllers is based on a linguistic phase plane [13] (see Fig. 6). Computing a fuzzy control using the linguistic plane in Fig. 6, with the rules presented in Table 1, it is possible design a controller with small/big rise time as well as small/big overshoot. This design methodology can be applied to design a robust and fast controller decreasing lifespan of power electronics or a moderate control effort in order to extending the lifetime.

Linguistic phase plane has the capability to moderate the control effort and to increase the lifetime of power electronics in BLDCM speed control. Control engineers and researchers should take into account this methodology to add interesting characteristics to their controllers, not given in terms of control performance, but in terms of economic savings, as well as a large lifetime in power electronic.
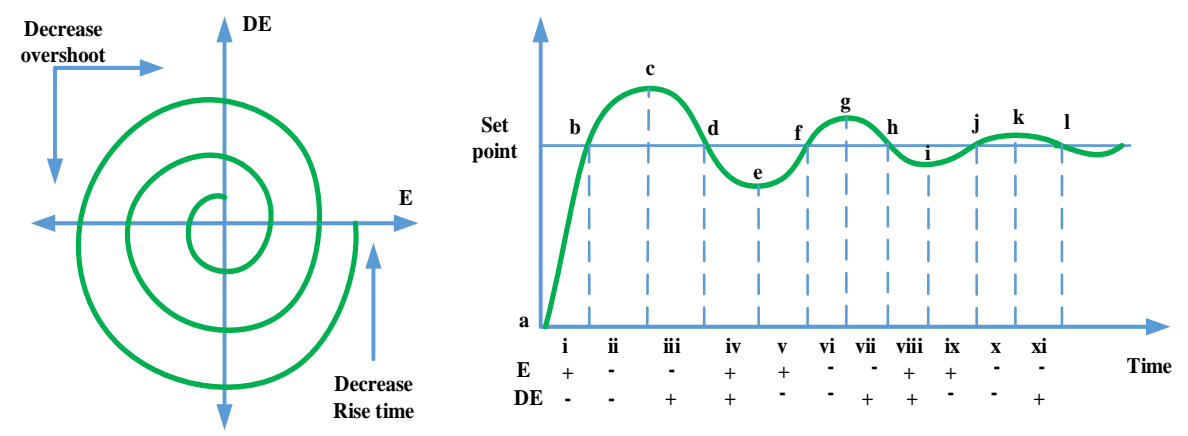

Fig. 6. Linguistic phase plane.

Table 1. Fuzzy control rules for Fig. 6 (N: Negative, Z:Zero, P:Positive, sp:set point, rt:rise time, os:overshot).

\begin{tabular}{cccccccccccc}
\hline & \multicolumn{1}{c}{ Reference Point } & \multicolumn{1}{c}{ Reference Point } \\
\hline Rules & 1 & 2 & 3 & 4 & 5 & 6 & 7 & 8 & 9 & 10 & 11 \\
\hline$E$ & $\mathrm{P}$ & $\mathrm{Z}$ & $\mathrm{N}$ & $\mathrm{Z}$ & $\mathrm{Z}$ & $\mathrm{P}$ & $\mathrm{N}$ & $\mathrm{N}$ & $\mathrm{P}$ & $\mathrm{P}$ & $\mathrm{N}$ \\
\hline$\dot{D E}$ & $\mathrm{Z}$ & $\mathrm{N}$ & $\mathrm{Z}$ & $\mathrm{P}$ & $\mathrm{Z}$ & $\mathrm{N}$ & $\mathrm{N}$ & $\mathrm{P}$ & $\mathrm{P}$ & $\mathrm{N}$ & $\mathrm{P}$ \\
\hline $\mathrm{CI}$ & $\mathrm{P}$ & $\mathrm{N}$ & $\mathrm{N}$ & $\mathrm{P}$ & $\mathrm{Z}$ & $\mathrm{P}$ & $\mathrm{N}$ & $\mathrm{N}$ & $\mathrm{P}$ & $\mathrm{Z}$ & $\mathrm{Z}$ \\
\hline & $\mathrm{a}, \mathrm{e}, \mathrm{i}$ & $\mathrm{b}, \mathrm{f}, \mathrm{j}$ & $\mathrm{c}, \mathrm{g}, \mathrm{k}$ & $\mathrm{d}, \mathrm{h}, \mathrm{l}$ & $\mathrm{sp}$ & $\mathrm{i}(\mathrm{rt}) \mathrm{v}$ & ii $(\mathrm{os}) \mathrm{vi}$ & iii,vii & iv,viii & ix & $\mathrm{xi}$ \\
\hline
\end{tabular}




\section{Co-simulation Topology}

Fig. 7 shows the block diagram implemented in Labview to execute co-simulation, this block diagram contains the block control and simulation loop useful to simulate control systems applications, and the block multisim design to stablish the communication with Multisim $^{\mathrm{TM}}$ software, where the power electronics and BLDCM are implemented. The electric circuit used in Multisim is presented in Fig. 1.

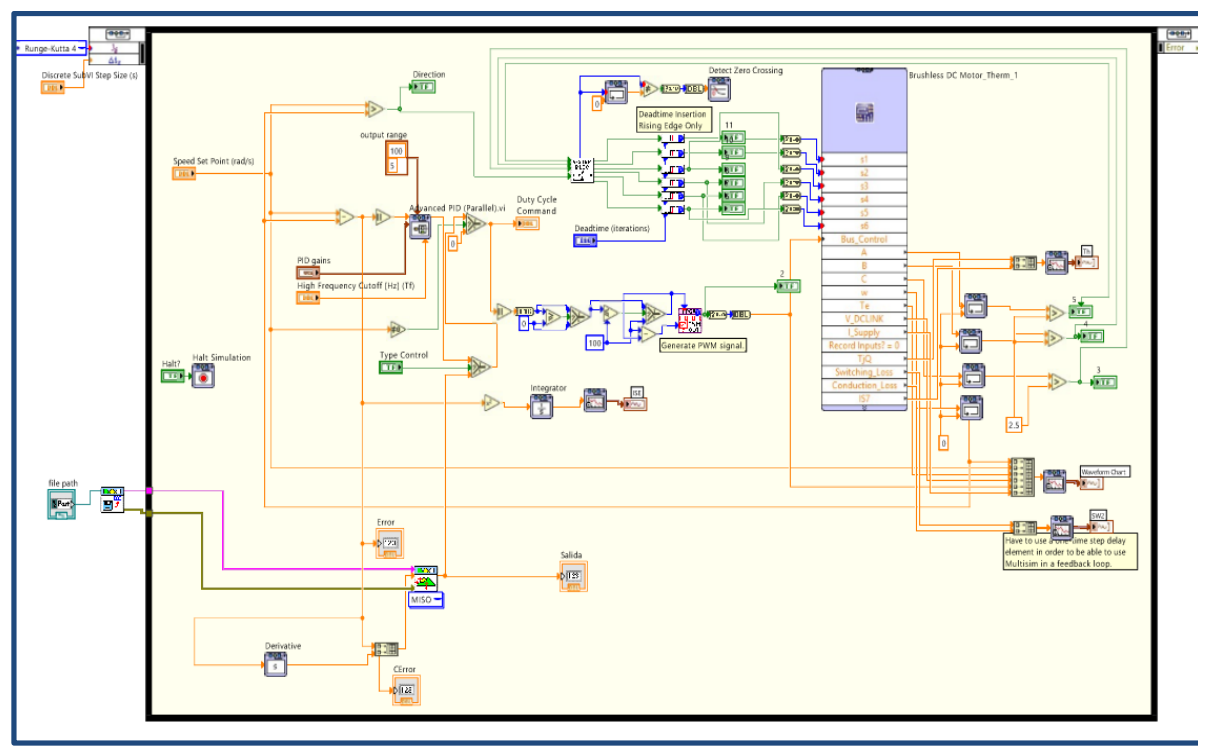

Fig. 7. Control system implemented in LabView ${ }^{\mathrm{TM}}$.

The parameters of the BLDCM are presented in Table 2. The fuzzy control in equation (13) is implemented using the Fuzzy Logic Toolbox, where input-output membership functions of Fig. 8 were programed. Centroid method defuzzification process is used in the rules shown in Fig. 9.

Table 2. Parameter of BLDCM.

\begin{tabular}{ccc}
\hline & Magnitude & Unit \\
\hline Stator Inductance & 0.15 & $\mathrm{mH}$ \\
\hline Stator Resistance & 0.6 & $\Omega$ \\
\hline Velocity constant & 0.03 & $\mathrm{Vs} / \mathrm{rad}$ \\
\hline Torque constant & 0.03 & $\mathrm{Nm} / \mathrm{A}$ \\
\hline Number of poles & 2 & \\
\hline
\end{tabular}




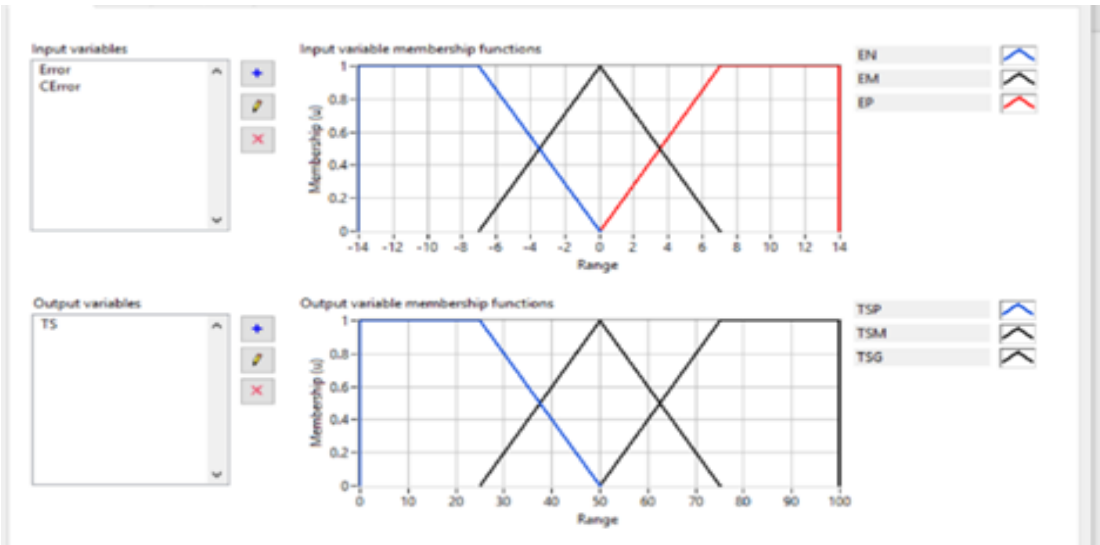

Fig. 8. Input-output membership functions.

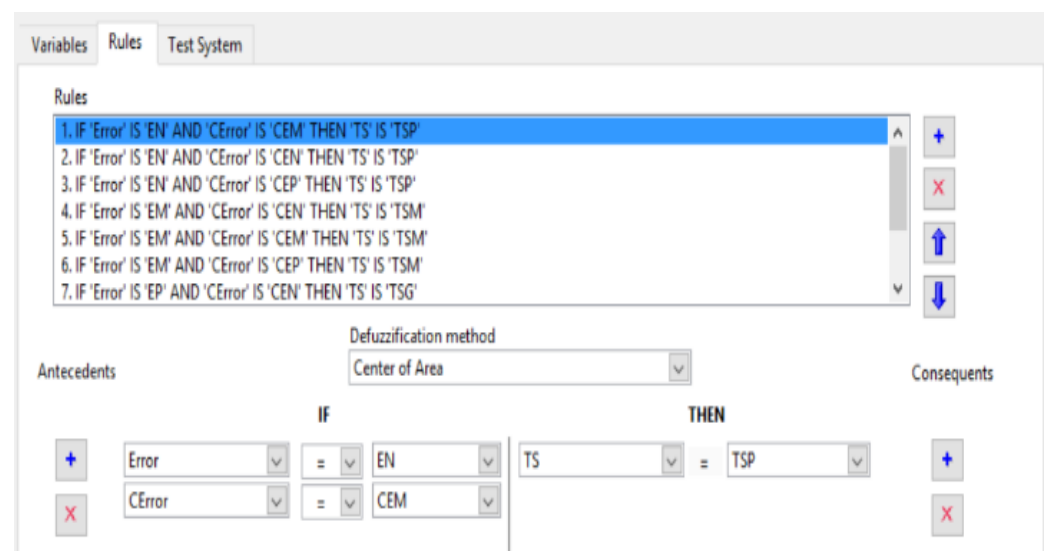

Fig. 9. Defuzzification rules.

\section{$5 \quad$ Results}

The parameters of the IGBT are presented in Table 3, and for determining the thermal conditions and life time cycle in the IGBTs, it is necessary to use the thermal information.

Thus, the relationship between the thermal impedance as function of pulse duration (see Fig. 10 (b)) and the power cycling lifetime curve are required to calculate the life cycles of the IGBTs in the power converter (see Fig. 10 (a)).

Applying the thermal information of the IGBT, it is possible to calculate the Cycles Before Failure $(C B F)$, by equation (4). Once $C B F$ is computed, the lifetime in years can be calculated by equation (5). 
Manuel García-López, José A. Rosales-Martinez, Pedro Ponce-Cruz, Arturo Molina-Gutiérrez, et al.

Table 3. Maximum ratings of IGBT 10-0B066PA00Sb-M992F09.

\begin{tabular}{ccc}
\hline Parameter & Value & Unit \\
\hline $\boldsymbol{V}_{\boldsymbol{C E}}$ & 600 & $\mathrm{~V}$ \\
\hline $\boldsymbol{R}_{\boldsymbol{C E}(\boldsymbol{O} \boldsymbol{N})}$ & 0.1 & $\Omega$ \\
\hline $\boldsymbol{I}_{\boldsymbol{C}}$ & $8-6$ & $A$ \\
\hline $\begin{array}{l}\boldsymbol{T}_{\boldsymbol{J}} \text { Junction } \\
\text { Temperature }\end{array}$ & 80 a 175 & ${ }^{\circ} \mathrm{C}$ \\
\hline $\boldsymbol{R}_{\boldsymbol{J}-\boldsymbol{S} \text {. Thermal }} \begin{array}{l}\text { Resistance } \\
\text { Junction to } \\
\text { Sink }\end{array}$ & 3,50 & $\mathrm{~K} / W$ \\
\hline
\end{tabular}

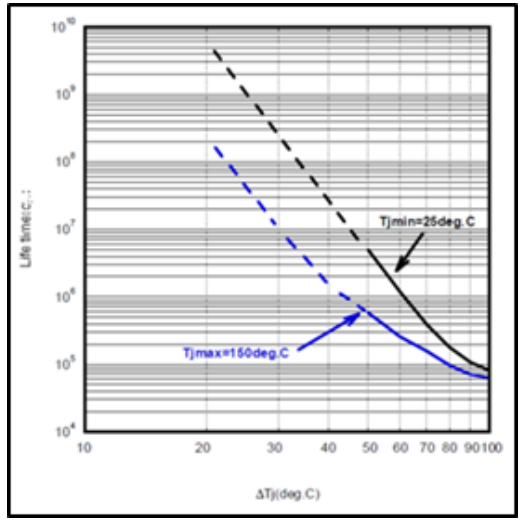

(a)

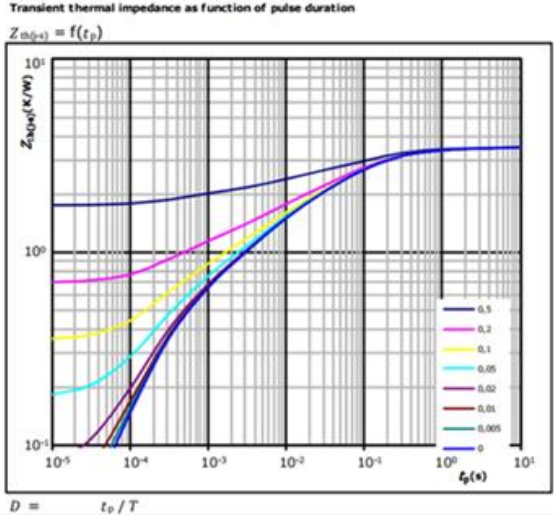

(b)

Fig. 10. (a) Power cycling lifetime curve, (b) Transient thermal impedance as function of pulse duration.

The brushless dc drive is evaluated tracking a desired speed with a fuzzy controller and a proportional control. The gain of the proportional control is $K=500$ and the fuzzy logic controller is designed in accordance to Figs. 8-9. The performance of proportional controller and the Fuzzy logic controller is presented in Fig. 11, where the fuzzy logic controller presents fast speed response and a lower controller index Integral Square Error (ISE).

On the other hand, the maximum temperature ripple is reached when the motor starts. Besides the increments in temperature are presented when the reference speed is changed, the proportional control and fuzzy logic controller track the reference speed (see Fig. 11 and Fig. 12).

As it is observed, the fuzzy logic controller allows to reach the speed reference with a lower ISE. Moreover, the fuzzy logic controller is able to maintain a lower value of 


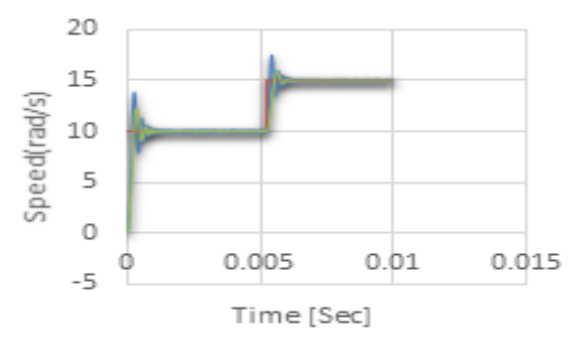

(a)

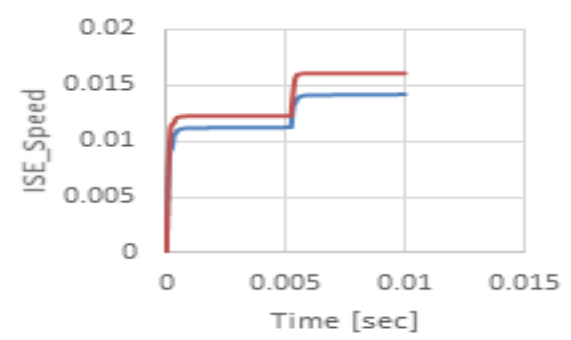

(b)

Fig. 11. (a) Speed response: proportional control (blue), Fuzzy logic controller (green), and set point (red); (b) Controller index Integral Square Error (ISE), proportional (red), Fuzzy logic (blue).

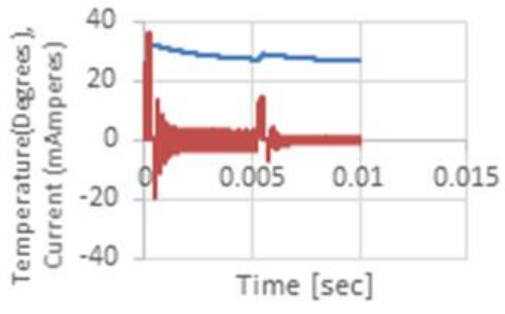

(a)

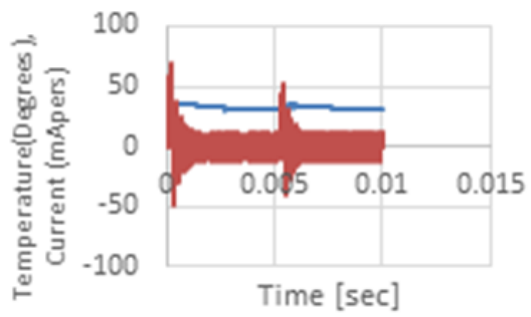

(b)

Fig. 12. Current and temperature into an IGBT when fuzzy controller is running (a) y proportional controller is running (b).

temperature when is tracking the reference speed. Fig. 13 shows the temperature response when the fuzzy logic and proportional controller are running.

The lifetime for this example is computed as follows: the fuzzy logic controller has a temperature maximum of $\mathrm{Tjmax}=32.382$, then $\Delta \mathrm{T}=\mathrm{Tjmax}-25^{\circ}=7.3382$. Using equation (7), it is obtained $C B F=19973870671$. Therefore, from equation (8) $M T B F=190.01$ [years]. For the proportional control the computation is: Tjmax $=$ 35.6447, $\Delta T=$ Tjmax $-25^{\circ}=10.6467, \quad C B F=541162959016419 *$ $\Delta T^{-5.12121}=2969916551$. Then $\mathrm{MTBF}=28.25$ years. The results are shows at the Table 4.

\section{Conclusions}

This paper demonstrates one way of increasing the lifespan of power electronics by means of implementation of fuzzy logic control. The results are verified in the application of fuzzy control for regulate the speed of a BLDCM. It is concluded that on-state and switching losses, as well as maximum temperature swing, are lower using fuzzy controller than using proportional controller. The proposal and comparison are validated via co-simulation Labview-Multisim in order to use accurate electric models of Multisim and advanced control design tools of Labview. Furthermore, Multisim 
Manuel García-López, José A. Rosales-Martinez, Pedro Ponce-Cruz, Arturo Molina-Gutiérrez, et al.

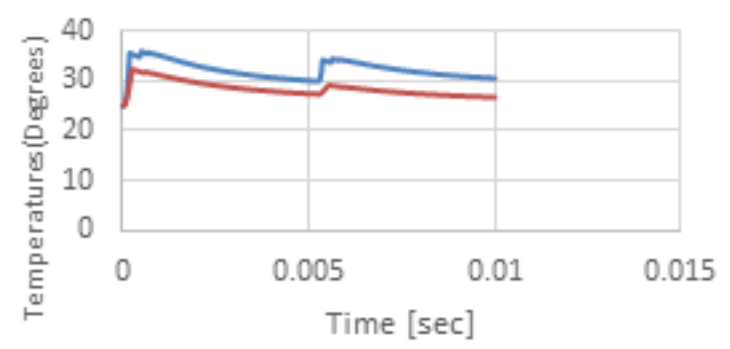

Fig. 13. Temperature into an IGBT: conventional control (blue); fuzzy control (red).

Table 4. Comparison of life time estimated with Fuzzy and Proportional control.

\begin{tabular}{lcccc}
\hline & Maximum Temp. & $\Delta \mathbf{T}=$ Tjmax $-\mathbf{2 5}^{\circ}$ & Power cycle & Years \\
\hline Fuzzy & Tjmax $=32.382$ & 7.3382 & 19973870671 & 190.01 \\
\hline Proportional & Tjmax $=35.6447$ & 10.6467 & 2969916551 & 28.25 \\
\hline
\end{tabular}

simulations gives estimation of temperature profiles necessary to computation of lifetime of power electronics.

Acknowledgement. This research is a product of the Project 266632 "Laboratorio Binacional para la Gestión Inteligente de la Sustentabilidad Energética y la Formación Tecnológica" [ "Bi-National Laboratory on Smart Sustainable Energy Management and Technology Training"], funded by the CONACYT SENER Fund for Energy Sustainability (Agreement: S0019201401).

\section{References}

1. Xia, C. L.: Permanent magnet brushless dc motor drives and controls. John Wiley \& Sons (2012)

2. Pillay, P., Krishman, R.: Application Characteristics of Permanent Magnet Synchronous and Brushless DC| motor for Servo Drives. IEEE transactions on industrial applications, 27(5) (1991)

3. Premkumar, K., Manikandan, B. V.: Speed control of Brushless DC motor using bat algorithm optimized Adaptive Neuro-Fuzzy Inference System. Applied Soft Computing, 32, pp. 403-419 (2015)

4. John-Prabu, M., Poongodi, P., Premkumar, K.: Fuzzy supervised online coactive neurofuzzy inference system-based rotor position control of brushless DC motor. IET Power Electronics, 9(11), pp. 2229-2239 (2016)

5. Ma, K., Vernica, I., Blaabjerg, F.: Advanced Design Tools for the Lifetime of Power Electronics - Study Case on Motor Drive Application. Proceeding of IEEE 8th International Power Electronics and Motion Control Conference (2016).

6. Power and productivity for a better world ${ }^{\mathrm{TM}}$ : Load-cycling capability of HiPak IGBT modules (2014) 
7. Parker, M. A., Soraghan, C., Giles, A.: Comparison of power electronics lifetime between vertical- and horizontal-axis wind turbines. IET Renew, Power Gener, 10(5), pp. 679-686 (2016)

8. Batunlu, C., Alrweq, M., Albarbar, A.: Effects of Power Tracking Algorithms on Lifetime of Power Electronic Devices Used in Solar Systems. Energies, 9, pp. 884, DOI:10.3390/en9110884 (2016)

9. Ponce-Cruz, P., Ramírez-Figueroa, F. D.: Intelligent Control Systems with LabVIEWTM. Springer (2010)

10. Introducción a la Co-Simulación Digital y Analógica entre NI LabVIEW Y NI Multisim: http://www.ni.com/white-paper/13663/es/ (2017)

11. Krishnan, R.: Electric Motor Drives: Modeling, analysis and control (2001)

12. Park, J. M.: Novel Power Devices for Smart Power Applications. Phd. Dissertation, University in Vienna, Austria (2014)

13. Lee, C. C.: Fuzzy Logic in Control Systems: Fuzzy Logic Controller. IEEE Transactions on systems, man, and cybernetics, 20(2), pp. 404-418 (1990)

14. INFINEON: Transient Thermal Measurements and thermal equivalent circuit models (2015)

15. Fuji: IGBT modules application manual. Fuji Electric Co., Ltd. URL. http//www.fujielectric.co.jp/products/semiconductor/ (2017)

16. http://www.springer.com/lncs, last accessed (2016) 